\title{
Time-motion analysis in the sport of dressage
}

\author{
Hilary M. Clayton \\ University of Saskatchewan, Saskatoon, Canada
}

\begin{abstract}
Summary
Time-motion analysis was applied in an analysis of the Fédération Equestre-Internationale (FEI) dressage tests. Each test was divided into a series of sequences; the distance of each sequence was measured, and the duration and average speed were determined from videotapes of five competitive performances. In general, as the level of difficulty increased, there was an increase in the duration of the tests and a reduction in average speed as the horse spent more time performing highly collected movements, such as the piaffe, passage and pirouettes. The medium and extended trot and canter involved short bursts of 10-15 seconds duration. Transitions were performed frequently, so considerable energy was expended in overcoming inertia. It is recommended that dressage horses competing at the FEl levels be conditioned using 7-9 minute periods of exercise that incorporate frequent transitions and short (10-15 second) bursts of extended trot and canter.
\end{abstract}

Keywords: $\quad$ time-motion analysis, equestrian sports, dressage, conditioning, exercise-physiology

\section{Zeit-Bewegungs-Analyse im Dressursport}

Bei FEl-Dressurprüfungen wurde die Dauer der Gangarten und Dressurlektionen anhand von Videoaufnahmen untersucht. Dafür wurde jeder Test in einzelne Abschnitte gegliedert.

Folgende Prüfungen wurden analysiert : der Prix St.Georg, die Intermediaire I und II sowie der Grand Prix und Grand Prix Special. Für jede Aufgabensequenz wurden Messungen durchgeführt, bei denen die Gangart, das Tempo und die Bewegungsrichtung der Pferde anhand von Videoaufnahmen festgehalten wurden. Bei jedem Ritt wurden nur die fehlerfrei gerittenen Sequenzen beurteilt und Fehler, welche einen oder mehrere Aufgabenteile andauerten, nicht mitgerechnet.

Die Auswertung der erhaltenen Daten zeigte die Tendenz, daß die Dauer eines Rittes entsprechend dem Schwierigkeitsgrad der Aufgabe zunahm. Gleichzeitig verringerte sich die durchschnittliche Geschwindigkeit der Pferde. Die in extremer Versammlung gerittenen Aufgabenteile wie Piaffe, Passage und Pirouetten benötigten viel Zeit und verlängerten die Gesamtdauer des Rittes. Die Sequenzen des Mitteltrabs, des starken Trabs und die Galoppeinlagen nahmen kaum Zeit in Anspruch; sie dauerten im Durchschnitt 10-15 Sekunden.

Es wurden häufig Übergänge geritten, die zum Überwinden der Trägheit einen höheren Energieverbrauch bewirken dürften. Beim Vergleich der einzelnen Pferde ergaben sich die größten Zeitunterschiede bei den Lektionen im Halten, welche eine Varianzbreite von $39 \%$ erreichten. Auch die Sequenzen vor und nach einem Anhalten waren unterschiedlich lang, die Varianz der Dauer dieser Aufgabenteile entsprach $21 \%$. Das Rückwärtsrichten nahm einen Variationskoeffizienten von $18 \%$ ein, je nachdem, wie prompt und mit welcher Geschwindigkeit die Pferde die Aufgabe erfülten. Insgesamt betrachtet zeigte die Zeit-Bewegungsanalyse jedoch, daß die durchschnittliche Dauer der meisten Aufgabenteile bei einem Variationskoeffizienten $<10 \%$ nicht sonderlich differierte.

Beim Vergleich der einzelnen Wettkämpfe untereinander stellte sich heraus, daß der Prix St.Georg eine beträchtlich längere Distanz (1356 m) beinhaltete als alle anderen Prüfungen, die zwischen 1124 und 1209 Metern Reitstrecke lagen. Die kürzeste Dauer eines Rittes betrug 388 Sekunden (Intermediaire I), die längste 474 Sekunden (Grand Prix Special).

Aus ihren Beobachtungen zog die Autorin den Schluß, daß ein Dressurpferd, welches an FEI-Prüfungen teilnimmt, so trainiert werden sollte, daß es bei häufigen Tempowechseln 7-9 Minuten lang seine Höchstform erreicht. Dieses Training sollte durch kurze Einlagen im Mitteltrab bzw. starken Trab oder durch kurze Galoppaden von 10-15 Sekunden Dauer ergänzt werden.

Schlüsselwörter: Zeit-Bewegungsanalyse, Reitsport, Dressur, Training, Leistungsphysiologie

\section{Introduction}

Preparation of the equine athlete for competition involves a combination of training and conditioning. Training develops mental discipline and teaches the horse to perform the technical skills. Conditioning improves performance through enhancing the horse's physiological capabilities and also reduces the risk of injury by strengthening the musculoskeletal tissues (Clayton 1991). The sport of dressage requires a prolonged technical training period in preparation for advanced competitions. The tests performed in competition are designed to en- courage the progressive development of technical skills, without necessarily taking account of physiological requirements. At the lower levels of dressage competition, the national equestrian federations develop a series of tests for use in national competitions. Time-Motion Analysis (TMA) of the Canadian Equestrian Federation dressage tests resulted in the formulation of guidelines for conditioning horses at the basic and medium levels of competition (Clayton 1993). In international competitions, tests developed by the Fédération Equestre In- 
ternationale (FEl) are used. In order of difficulty these are the Prix St. Georges, Intermediare I, Intermediare II, Grand Prix and Grand Prix Special.

The development of an appropriate conditioning programme requires some background knowledge about the physiological demands of competition. In sports that have a fairly constant exercise intensity, such as racing, a simple review of the intensity and duration is usually adequate. For sports that have an intermittent pattern of energy expenditure, TMA is a simple and versatile technique for providing a breakdown of the temporal aspects of the competitive performance. It involves videotaping a competition, then using a stopwatch to measure the time spent in different types of activity, computing the ratios between the time segments, and using the information to develop a sport-specific conditioning programme that mimics the competitive performance (Alexander and Boreskie 1989). In human sports TMA has been applied to study and develop conditioning programmes in a number of sports (Francis 1952, Reilly and Thomas 1976, Alexander and Boreskie 1989).

This paper describes the application of TMA to study the five FEl dressage tests. The objectives were firstly, to determine whether these tests encourage the progressive physiological development of the horse, and secondly, to gather information that could be used as a basis for developing conditioning programmes for high level dressage horses.

\section{Materials and Methods}

The tests studied were the FEI (1987) dressage tests: the Prix St Georges (PSG), Intermediare I (Int I), Intermediare II (Int II), Grand Prix (GP) and Grand Prix Special (GPS). Each test was divided into a series of sequences; the criteria used to define the sequences included gait (halt, walk, trot, canter, piaffe, passage, rein back), gait type (collected, medium, extended) and movement (demi-pirouette, pirouette, shoulder in, half pass, tempi changes). The distance covered during each sequence was calculated from a knowledge of the dimensions of the dressage arena, assuming that when a right angled turn was required the horses actually performed a quarter circle of $6 \mathrm{~m}$ diameter. The total distance of the test was computed as the sum of the distances of the individual sequences.

Videotape recordings were made during competitions. A camcorder was set up on a tripod $20 \mathrm{~m}$ from a corner of the arena, so that the entire arena could be seen when the camera was panned. The complete test was recorded starting just before the horse entered the arena and ending after the final salute. All the tests in a competition were recorded, but those in which the horse or rider made an error that affected the duration of one or more sequences were excluded from further analysis. After screening out the tests that included errors, five competitors were chosen at random for analysis at each level of competition. The scores and placings were not taken into account since this study was concerned only with the physiological aspects of the performance.

During the video recordings a stopwatch was superimposed on the videotape. During replay the time taken to perform each sequence was measured from the stopwatch readings, and the average speed of the sequences was calculated as the distance divided by the time taken. For each test the total duration was computed as the sum of the sequence durations, and the average speed was calculated from the total distance divided by the total time. The amount of time and percentage of the total time spent in each type of activity were calculated. Statistical analyses were performed using the Statistical Packages for the Social Sciences (SPSS/PC+, SPSS Inc., Chicago, Illinois). For each of the five tests studied, mean values and standard deviations were determined for the temporal measurements. The coefficient of variation (CV), which expresses the standard deviation as a percentage of the mean, was computed as an indication of the consistency of the sequence durations between different horses. The average speed was determined for the individual sequences and for the test as a whole.

\section{Results}

The total number of sequences, total distances, total times and average speeds of the different tests are shown in table 1 ,

Tab. 1: Summary statistics for the Prix St. Georges (PSG), Intermediare I (Int I), Intermediare II (Int II), Grand Prix (GP) and Grand Prix Special (GPS) dressage tests.

\begin{tabular}{|l|c|c|c|c|c|}
\hline & PSG & Int I & Int II & GP & GPS \\
\hline $\begin{array}{l}\text { Number of } \\
\text { Sequences }\end{array}$ & 44 & 34 & 42 & 45 & 41 \\
\hline $\begin{array}{l}\text { Total Dis- } \\
\text { tance }(\mathrm{m})\end{array}$ & 1356 & 1134 & 1126 & 1131 & 1209 \\
\hline $\begin{array}{l}\text { Total Time } \\
(\mathrm{s})\end{array}$ & 451 & 388 & 421 & 463 & 474 \\
\hline $\begin{array}{l}\text { Average } \\
\text { Speed }(\mathrm{m} / \mathrm{s})\end{array}$ & 3.01 & 2.93 & 2.67 & 2.45 & 2.55 \\
\hline
\end{tabular}

and the breakdown of the time spent in different movements is shown in table 2. The majority of time was spent in the collected gaits, with the medium and extended trot and canter occurring in short bursts of 10-15 seconds duration.

For most of the sequences, the CVs were below $10 \%$ with a few notable exceptions; the halt sequences had the highest CVs (up to 39\%) as a result of variations in how long the halt was sustained by different riders. High CVs (up to $21 \%$ ) were also recorded for sequences preceding and following those that were performed between two markers rather than at a specific place in the arena, such as the pirouettes. The rein back sequences had CVs up to $18 \%$ due to marked differences between horses in the promptness and speed of the steps.

\section{Discussion}

For the purposes of TMA, evaluation of the performance of five horses at each level of competition was considered sufficient since the time-motion characteristics of a sport tend to be quite consistent between performances. Indeed, it has been suggested that the analysis of as few as two performances is representative (Alexander and Boreskie 1989). In this study the variation in the times recorded for different horses performing the same movements was small as shown by the fact that the CV was below $10 \%$ for most sequences. Higher CVs were recorded for sequences in which the rider had some choice in how long a movement was sustained (e.g. the halt) or when the rider was able to exercise some discretion as to where a 
Tab. 2: Percentages of total time spent performing different movements and (number of sequences of each movement) in the Prix St. Georges (PSG), Intermediare I (Int I), Intermediare II (Int II), Grand Prix (GP) and Grand Prix Special (GPS) dressage tests.

\begin{tabular}{|c|c|c|c|c|c|}
\hline Movement & PSG & Int I & Int II & GP & GPS \\
\hline Halt & $3.41(3)$ & $5.06(4)$ & $4.88(4)$ & $2.46(2)$ & $2.28(2)$ \\
\hline Collected walk & 9.47 (3) & $9.66(4)$ & $9.93(5)$ & $11.17(4)$ & $5.16(1)$ \\
\hline Extended walk & $7.09(1)$ & $7.62(1)$ & $8.49(1)$ & $6.58(1)$ & $7.63(1)$ \\
\hline Demipirouette walk & $1.71(2)$ & & & $1.62(2)$ & \\
\hline Collected trot & $14.30(8)$ & $18.08(4)$ & $22.69(10)$ & $12.50(6)$ & $12.17(6)$ \\
\hline Medium trot & $2.42(1)$ & $3.00(1)$ & $2.94(1)$ & & $2.25(1)$ \\
\hline Extended trot & $5.37(2)$ & $2.71(1)$ & $5.67(2)$ & $5.14(2)$ & $5.75(3)$ \\
\hline Shoulder in trot & $3.60(2)$ & & & & \\
\hline Half pass trot & $3.77(2)$ & $5.11(1)$ & $5.54(1)$ & $4.94(2)$ & $4.92(2)$ \\
\hline Passage . & & & & $17.40(6)$ & $22.18(8)$ \\
\hline Piaffe & & & $2.43(2)$ & $4.60(3)$ & $5.11(3)$ \\
\hline Collected canter & $33.12(11)$ & $29.63(9)$ & $19.30(8)$ & $15.37(10)$ & $14.29(7)$ \\
\hline Medium canter & $2.10(1)$ & & & $2.64(1)$ & $1.78(1)$ \\
\hline Extended canter & $2.07(1)$ & $2.30(1)$ & $2.40(1)$ & $2.15(1)$ & $4.34(1)$ \\
\hline Half pass canter & $3.34(2)$ & $4.23(1)$ & $3.76(1)$ & $4.62(1)$ & \\
\hline Demipirouette canter & $1.46(2)$ & & & & \\
\hline Pirouette canter & & $2.67(2)$ & $2.46(2)$ & $2.03(2)$ & $1.92(2)$ \\
\hline 4 tempi changes canter & $3.18(1)$ & $3.73(1)$ & & & \\
\hline 3 tempi changes canter & $2.89(1)$ & $3.62(1)$ & & & \\
\hline 2 tempi changes canter & & & $3.67(1)$ & $3.27(1)$ & $3.32(1)$ \\
\hline 1 tempi changes canter & & & $4.01(1)$ & 3.51 (1) & $6.89(2)$ \\
\hline Reinback & $0.70(1)$ & 2.57 (3) & $1.83(2)$ & & \\
\hline
\end{tabular}

sequence was performed in the arena (e.g. the sequences preceding and following the canter pirouettes).

The PSG test covered a considerably longer distance (1356 m) than any other FEI test. The distance of the Int I, Int II and GP tests were all in the range of 1124 to $1134 \mathrm{~m}$, with the GPS being slightly longer (1209 m). There was a progressive reduction in the average speed of the tests from PSG $(3.01 \mathrm{~m} / \mathrm{s})$ to GP $(2.45 \mathrm{~m} / \mathrm{s})$ and GPS $(2.55 \mathrm{~m} / \mathrm{s})$. The slower average speed at the higher competitive levels was due to the fact that a greater proportion of the time was spent performing the collected gaits. However, the slow speed of the collected gaits is misleading in terms of energy expenditure, since considerable muscular effort is required to maintain the collected carriage. This is particularly true for the piaffe and pirouettes which are performed on the spot and have zero velocity but are associated with relatively high heart rates (Clayton 1989).

The number of sequences gives an indication of the number of transitions performed. This is an important consideration in formulating a conditioning programme because each time the speed or direction of movement changes energy is used to overcome inertia. Therefore, each transition increases the energetic requirement above what would be expected from the speed alone. With the exception of the Int II test which has only 34 sequences, the other four FEl tests have $41-45$ sequences. This is more than the Canadian Equestrian Federation's tests which have an average of 20 sequences at basic level and 39 sequences at medium level (Clayton 1993). Therefore, as horses progress through the levels of dressage competition transitions occur more frequently with a consequent rise in the inertial energy expenditure.

In designing a cardiovascular conditioning programme for a specific sport and a particular level of competition, TMA gives an indication of the relative contributions of aerobic and anaerobic metabolism. Highly aerobic sports are characterised by a low or moderate exercise intensity and a duration in excess of 3 minutes. Highly anaerobic sports involve a high exercise intensity corresponding to heart rates that exceed the anaerobic threshold of $150-160$ beats/min (Persson 1983). Due to the effects of lactate accumulation anaerobic exercise can be sustained for short periods only. Therefore, sports that are highly anaerobic have either a short duration or short bursts of anaerobic work superimposed on an aerobic base (Clayton 1991).

The total duration of the FEl dressage tests ranged from 388 seconds in the Int I to 474 seconds in the GPS, indicating that aerobic metabolism is likely to be the primary metabolic pathway for energy production in dressage horses competing at 
advanced levels. The heart rate of a horse performing the GP test in a training environment was in the range of 61-141 beats/min (Clayton 1991). Since the anaerobic threshold is usually crossed at heart rates in excess of 150-160 beats/min (Persson 1983), the heart rates recorded during the GP test are consistent with a primarily aerobic workload. However, the relatively low heart rates do not preclude some lactate build up (Bayly 1989) due to the muscular effort involved in the technically difficult movements, such as the piaffe, passage and pirouettes.

A horse's heart rate response to exercise is linearly related to work-load for heart rates in the range of 120-200 beats/min (Ehrlein et al. 1973). Below 120 beats/min psychogenic factors have a marked influence, and above 200 beats/min the heart rate response flattens out as maximal heart rates are approached (Persson 1983). Dressage horses show an increase in heart rate with speed. For example, the heart rate is around 80-100 beats/min in the collected trot rising to 110-130 beats/min in the extended trot. In the collected and extended canters heart rates are in the range of 100-120 and 130-160 beats/min respectively. Lateral movements such as the shoulder in and half pass, which are performed in the collected gaits, are associated with heart rates that are about 20 beats/ min higher than for the collected gaits (Clayton 1989). A similar finding has been reported in human athletes, who have higher heart rates when moving sideways or backwards than when moving forward at the same speed (Alexander and Boreskie 1989). Technically difficult movements, such as the piaffe, passage and pirouettes are associated with much higher heart rates (120-160 beats/min) than would be expected from the speed of progression (Clayton 1989).

The results of this study suggest that cardiovascular fitness is not a limiting factor in the performance of advanced dressage horses. Fitness workouts for these horses should be based on 7-9 minute exercise periods, with frequent transitions between and within the gaits; a more abrupt transition with a greater change in speed (e.g. collection to extension) exaggerates the inertial effects of the transition. The extended gaits are performed in 10-15 second bursts. Progressively increasing periods of the technically difficult movements should be used to build muscular strength and endurance in a sport specific manner. In addition to the FEl tests described in this paper, dressage horses compete in free style competitions. In designing a free style test, the trainer should take account of the physiological requirements; if the energetics of the free style performance are significantly different from those of the FEI tests, specific conditioning exercises should be incorporated in the workouts to ensure that the horse is adequately prepared.

\section{References}

Alexander, M. J. L. and Boreskie, S. L. (1989): An analysis of fitness and time-motion-characteristics of handball. Am J Sports Med 17, 76-82.

Bayly, W. M. (1989): The energetic basis of exercise. In: Equine Sports Medicine. Ed. W. E. Jones, Lea and Febiger, Philadelphia, pp 11-18.

Clayton, H. M. (1989): Time-motion analysis in equestrian sports: the Grand Prix dressage test. Proc Am Assoc Equine Pract 35, 367-373.

Clayton, H. M. (1991): Conditioning sport horses. Sport Horse Publications, Saskatoon, pp 33-43, 77.

Clayton, H. M. (1993): Development of conditioning programs for dressage horses based on time motion analysis of competitions. J Appl Physiol 74, 2325-2329.

Ehrlein, H. J., Hornicke, H., Engelhardt, W. von and Tolkmitt, G. (1973): Heart rate frequency during standardized exercise as a measure of the working capacity of horses. Zentrbl Veterinärmed 20A, 188-208.

Francis, R. J. (1952): An analysis of certain time, motion and timemotion characteristics in eight athletic sports. PhD Dissertation, The Ohio State University.

Mayhew, S. R. and Wenger, H. A. (1985): Time-motion analysis of professional soccer. J Hum Move Stud 11, 49-52.

Persson, S. G. B. (1983): Evaluation of exercise tolerance and fitness in the performance horse. In: Equine Exercise Physiology. Ed Snow, D. H., Persson S. G. B. and Rose R. J. Granta Editions, Cambridge, pp 441-457.

Reilly, T. and Thomas, V. (1976): A motion analysis of work rate in different positional roles in professional football match play. $J$ Hum Move Stud 2, 87-97.

This project was supported by a grant from Sport Canada. The author thanks Norbert Christman for technical assistance.

\section{Hilary Mary Clayton}

Department of Veterinary Anatomy

Western College of Veterinary Medicine

University of Saskatchewan

52 Campus Drive

Saskatoon

Saskatchewan S7N 5B4

Canada 